\title{
Developing the Curriculum in an Innovative Greek School Framework: The Implication of Teachers
}

\author{
Vassilis Tsafos ${ }^{1, *}$ \\ ${ }^{1}$ Early Childhood Education Department, University of Athens, Athens 10680, Greece \\ *Correspondence: University of Athens, Navarinou 13A, Athens 10680, Greece \\ Tel: 30-210-368-8567_E-mail: tsaf@otenet.gr; vtsafos@ecd@ecd.uoa.gr
}

Received: November 1, $2012 \quad$ Accepted: December 10, $2012 \quad$ Online Published: January 16, 2013

doi:10.5430/jct.v2n1p42 URL: http://dx.doi.org/10.5430/jct.v2n1p42

\begin{abstract}
The paper presents an alternative practice, a school based curriculum development, less standardised and bureaucratic than the typical, implemented in Second Chance Schools (SCS), focusing on the different role of educators in terms of curriculum development. In this context, it will be presenting the first results of a research ongoing on the ways the educators themselves perceived and managed this new and unprecedented and unusual for them role, as curriculum developers. The educators' attitudes were recorded based on data collected by questionnaires with open-ended questions, completed by the educators of four SCSs. In the discussion part emphasis is placed on the ways the educators analyse the new educational situation as well as their attitude and the effects they believe that it has broadly in the educational process and in their educational theory.
\end{abstract}

Keywords: school based curriculum development; teacher initiative; practical and critical approach

\section{Introduction}

As the Curriculum is said to be the soul of education, it would not be too far-fetched to identify serious malfunctions in Greek educational practices, in terms of curriculum development. Ever since the beginning of curriculum development, regardless of the term used, we never succeeded in overcoming this practice, based on Tyler's technical rationality (1949): experts own theory and design the curriculum in every step and detail, and then call educators to 'consume' this single unique product, which is the same for all students, despite the undeniable particular features of each student population and educational context in which the curriculum is to be taught. However, this traps educators into attempting to conform to specific steps and ways to achieve specific predetermined objectives.

There are, however, other practices, less standardised and bureaucratic, which offer a new perspective to the role of educators in the educational process and education in general. This paper presents such an alternative practice, implemented in Second Chance Schools, focusing on the different role of educators in terms of curriculum development. In this context, I will be presenting the first findings of a research on how the educators themselves perceived and managed this new and different role, as agents of curriculum development.

\section{Theoretical Framework: The Role of Educators According to the Theoretical Approach of the Curriculum}

The debate on the role of educators in curriculum development started from the movement of progressive pedagogy, as a reaction to the $19^{\text {th }}$ century classical curriculum, which was based on the Herbartian logic of standardised teaching and the transfer of a body of knowledge, deemed valuable by experts, which leads to the development of the mind. In the context of industrial economic development and social efficiency for a functional society, Dewey was one of the first to promote educator autonomy as a main parameter of school development and the educator as a main agent of curriculum design and development.

\subsection{The 'Scientific' Approach to the Curriculum}

In the context of the 'scientific' approach to education, as defined by positivism in the first half of the $20^{\text {th }}$ century, 
the curriculum was viewed as a product, a fait accompli, produced by experts on academic theory, independent from the educational act. This technocratic approach turned curriculum development into a bureaucratic normative and therefore controlling process, where educators received and implemented orders.

Such an approach can limit the educators' wish for autonomy (Hargreaves 1994), depersonalising educators (Lawton 1980) and turning them into agents that guide students through the pages of textbooks focusing on the subject matter (Flouris 1995), forced to implement a predetermined syllabus. In this way, bureaucratic protocols hold the educators responsible for the process, forcing them to waive their professional power and moral responsibility for the curriculum they teach (Pinar 2004: 3-4). Schools are therefore turned into a hybrid, between a bureaucratic organisation and a business. As agents of the system, educators can only conceive their mission in business terms, such as competition, productivity, efficiency, market needs...

This approach can also lead educators to the opposite practice: feeling the divergence between theory and practice, educators refuse to implement the suggested curriculum, creating obstacles for any innovation, change or reform. In this way, they put themselves in a position where they are accused of being the conservative source of failure for most changes (Westbury 1998: 52-53). The worst part is that educators return to their 'own' curriculum, often based on unconsciously adopted professional routines, drawing on their long experience from the existing educational norm, which does not allow them to think of any other practice (Hargreaves, 1994). Isolated in the safe haven of the school classroom, they have no opportunity to approach specific practices in a critical way and try out alternative practices.

\subsubsection{Alternative practices: A practical approach}

Since the 1960s a number of economic, social and epistemological changes have led to different approaches to education in general and the curriculum in particular. Regarding the curriculum, it can be supported that the reaction to Tyler's dominant technocratic model manifested itself through two alternative orientations, which, according to Grundy (1987) relate to the epistemological advancement that led to new epistemological paradigms:

The first alternative involves a practical approach to the curriculum using Stenhouse's process model, through which we can overcome the epistemology of explaining and verifying and move on to the epistemology of investigating and interpreting. According to Stenhouse, the curriculum cannot be a 'product' that comes to the school ready to be consumed, but 'hypothetical realisations of theses about the nature of knowledge and the nature of teaching and learning' (Ruddock \& Hopkins, 1985: 65), that is 'an educational proposal in such a form that it is open to critical scrutiny and capable of effective translation into practice' (Stenhouse 1975: 4). By linking the development of such a curriculum to the development of educators (Norris 2008: 5), he demonstrates that substantial curriculum development requires research, which is conducted by educators in their class, allowing them to scrutinise their ideas through their practice.

This framework led to the idea of curriculum development conducted by educators in their schools, so that it would meet the main needs of their specific student populations (Kelly 2004: 115). In this way, curriculum development can be viewed as a continuous process of curriculum adjustment and enhancement which takes place in the classroom, without overlooking or disparaging theory. This movement reinforces the autonomy of both educators and the school as an institution, promoting a 'bottom-up' view on curriculum development, curriculum theory production, and educator development, which are viewed as interrelated processes.

Of course, research in the classroom requires the development of practical wisdom (Elliott 1993) and calls for practitioners who are capable of conducting research, that is professional reflective educators. An important contribution here is represented by Schön's 'reflective practitioners', who function as practitioners, overcome the limitations of bureaucracy and inertia, and learn from experience, for experience and through experience. Schön's 'epistemology of practice' (Doll 1993: 47), as defined by Munby and Russell (1989), allows practitioners to:

* approach problems not as cases of generalised theory but as unique, individual cases, focusing on the non confirmed aspects of the problem, instead of implementing rules,

* contextualise the problem, so as to identify the values and norms to which they have given priority and perceive the possibility of alternative practices (Schön 1983: 310),

* place their objectives and means to public scrutiny, engage in dialogue with the situation, and enter into reflective discussion with their colleagues, so as to provide their reflection with feedback and enhance the situation.

\subsubsection{A critical approach}

The second reaction to the mechanistic, technocratic and normative model of curriculum development comes from 
critical pedagogy. Drawing on neomarxist theory, critical pedagogy promotes a critical stance towards education, including a critical approach to the curriculum. Arguing that no decision on the curriculum can be independent from values and ideology, critical pedagogy argues that the curriculum constitutes a social construct, and therefore its design is a political and ideological issue (Grolios, 2005: 18). Consequently, we can only understand the curriculum by approaching it in its social, economic and political context.

By viewing ideology as " a way of viewing the world, a complex of ideas, various types of social practices, rituals, and representations that we tend to accept as natural and as common sense" (McLaren 1989: 205), the critical approach supports that education uses the curriculum, be it written and official or latent and implicit, so as to present meanings serving a specific status quo as something natural and as common sense. In contemporary society, the curriculum is not neutral; it is the social product of conservative forces seeking to reproduce a social situation (Apple 1988: 201).

In the perspective of emancipation and active intervention for social change, the curriculum cannot be left in the hands of experts. Freire was the first to openly challenge the experts' authority to take decisions on curriculum design. By setting the political objective of radical social reformation with a socialist orientation and the educational objective of nurturing critical consciousness, which serves as the basis for achieving social reformation, he transfers authority from experts to the agents of the educational process, that is to students and teachers. The task of educators is to define the framework of this process, drawing on how they perceive social reality (Grolios 2005: 269). For Freire, obtaining knowledge is an active force used by learners in order to attribute meaning to their own lived world (Grolios 2005: 138).

According to critical pedagogy, simply grounding curriculum development on student experience is not enough for the curriculum to gain critical orientation. The experiences of both students and teachers must become the object of dialogue and negotiations and be recognised as problematic, perhaps even as the result of misrepresentations imposed along with specific meanings (Grundy 1987: 105). By identifying meaning as a social construct, students are encouraged to investigate and therefore to challenge their ways of interpreting society and its problems, which may appear natural when they are, in fact, constructed. In this way, they come to realise the mechanisms that reproduce reality, in effect oppressing them. Through praxis, that is conscious and rational action in an unbound non preconstructed dialogue with reality, students are liberated from false consciousness and the adoption of the values and ways of thinking of the dominant social class (Strike 1989 in Chatzigeorgiou 1998: 473). They come to seek and even express their voice, searching for alternative realisations of reality through the construction of different meanings (Freire 1972: 60-61).

The curriculum is neither a package of knowledge ready to be transferred to students nor a product used to achieve predetermined objectives. Nor is it a series of plans to be implemented in the context of specific principles, not even through research and reflection. In contrast, it is developed in real learning situations, through an active process where planning, acting and evaluating not only are interrelated but also form part of the process itself. It is a process in which students and educators engage in a dialectical search for alternative meanings (Grundy 1987: 115-116), and which accepts and perhaps even invites conflict, instead of excluding it (Giroux 1981).

The idea of educators developing the curriculum, either with a practical or with an emancipatory orientation, undermines traditional hierarchy in which educators are at the bottom of the educational pyramid, with curriculum designers and researchers being at the top, as producers of scientific knowledge. In this way, control over which educational knowledge is valid and which meaning(s) is (are) valuable in the educational process is taken away from external agents and attributed to schools (Keiny 1993: 67).

\subsubsection{Contemporary practices: new control mechanisms and postmodern searches}

Despite the various alternative orientations, in most Western countries educational policy since the 1980s has returned to the old controlling mechanism, albeit in a slightly different way (Autio 2003: 305). According to Kelly (1999), the appearance of neoliberal discourse and conservative political practices is governed by the following principles: simplified content of stable measurable principles, instrumentalisation, commercialisation, and an increasing emphasis on management. In this way, we return to centralised, fixed and recycled closed systems, which strive for balance and are disturbed by turbulence and decentralised practices (Doll 1993: 14). For educators, this means that they 'are or should be merely operators, passive agents, technicians rather than professionals, whose task is to carry out the policies made for them elsewhere and by others, to instruct children in those things their political masters wish to have them instructed in; [...] Whether, in reality, teachers can be thus operated by remote control is, [...] highly questionable, but it is certainly a premise and an assumption of current policy that they can and should be' (Kelly 2004: 189). 
To which extent does this orientation relate to the deprofessionalisation and the limiting of the educators' autonomy? In describing the different phases of the educators' professional development (2000), which are linked to the role attributed to educators throughout the educational act, Hargreaves refers to various scenarios of development in the postmodern period since 1980. Both the deprofessionalisation and the measurable professionalisation of accountability contort the movement and return it to previous controlling and normative discourses. Neoliberal discourse has been assimilated by education, in the context of global economic growth, which commercialises education to serve the needs of a specific type of economic development (Hargreaves 2000).

In contrast, according to Hargreaves, a postmodern professionalism, that is open, democratic and non exclusory, can only be implemented through a conscious social movement by educators. This movement would lead to the creation of new collective entities, like professional communities of learning, where educators realise that they have to work collectively, adopting a cooperative educational culture both in the school and in cooperation with the community and the administration, with the objective of providing all learners with education.

This framework could create the conditions for the curriculum to be viewed as praxis, that is as a means for 'interaction and communication between individuals who participate in a process that attributes meaning to the educational act' (Koutselini 2001: 1). The curriculum can actually respond to the challenges of postmodern insecurity, acting as a kaleidoscope that shifts orientations to reflect new visions and emancipatory aspects of learning and life (Slattery 1995: 257). Thus teachers, who are at the heart of education, have the opportunity to play a key role in collectively supporting an open postmodern curriculum that overcomes the closed determinism of physical objective reality, so as to seek ideas, values and attitudes that support both the critical approach to 'constructed' reality and new alternative ways of attributing meaning to it (Papastephanou \& Koutselini 2006: 163).

\section{The Research}

\subsection{Research Methodology}

The research presented here was conducted on June 2009, with educators from four Second Chance Schools (SCS) from different areas of Greece (Ioannina, Pyrgos, Kallithea, Thessaloniki). Overall, 42 fully or partially completed questionnaires were collected. Since the sample was not chosen through stratified random sampling, it cannot be considered representative. However, the research on the educators' views did not aim to draw generalisable conclusions. My aim was to draw on the empirical data of the research in order to express certain speculations on the educators' attitude towards the curriculum and its development, focusing on educators who followed alternative curriculum development practices in their school.

Data was only collected by administering questionnaires with 20 questions, which emerged from literature review and previous research on SCS educators (Tsafos 2008), in line with the research objectives. The questions addressed: a) the educators' individual and professional characteristics, b) their views on their attitude towards developing the curriculum themselves and on the factors that influenced them, and c) their views on the curriculum and how to utilise it both in SCSs and in conventional education reference schools.

The questionnaire included five closed questions, which are considered appropriate for researching attitudes and facilitate the statistical elaboration of the answers, which was conducted using the SPSS15 statistical analysis software. This paper will present a descriptive analysis of the data, which are particularly important in terms of the research objectives. The questionnaire also included six open and five semi open questions, that required participants to justify their answers. The elaboration of the participants' answers to the open and semi-open questions was performed using content analysis on the frequency and content of their answers.

\subsection{Research Questions}

Based on the data collected and the research objectives, the research questions formed as follows:

* What is the educators' attitude towards the curriculum development process?

* How do educators who develop curriculum in their school perceive the educational process?

* What is the role of the collective dynamics developed in the school in the context of alternative curriculum development?

* What meaning do educators attribute to the curriculum through this experience, in terms of the microlevel of the teaching act and the macrolevel of the broad social and cultural context? 


\subsection{The Educational Context of the Research}

Second Chance Schools (SCSs) started working in Greece in 2001, as part of a European programme on adult education aiming at eliminating functional illiteracy and social exclusion. They are intended for individuals who for some reason have left compulsory education in the second tier and now desire to complete their education. SCSs fall under lifelong learning, and aim at providing adult learners with the skills that will allow them to access higher education and the labour market, and more importantly to gain critical understanding of the diverse representations of today's world. This effort is governed by the theory of multiliteracies, which refers to contemporary citizens as critically literate in various complex levels of activity. The educational philosophy that was gradually developed in SCSs created a framework that would help learners familiarise themselves with how to manage these sites and reference situations (social, communicational, political, economic, etc.) and get acquainted with various ways of constructing meaning, so as to be able to integrate in social life (in the broadest sense of the term), actively participate in processes of political and social emancipation, manage their everyday life more efficiently, and deal with their problems in a rational way.

The scientific team responsible for designing the programme believed that SCS learners, who would be awarded a certification equivalent to High School diploma after completing two years of study, were not supposed to enter an educational environment similar to the one that had originally rejected them. For this reason, SCSs were given the opportunity to shape their internal educational policy on school level, in ways that were unprecedented in Greek education.

Specifically, each school unit, led by the educators, would:

- shape the syllabus, determining its structure and content to a great extent, and then use it to choose educational activities and organise alternative teaching practices (e.g. free laboratories, interdisciplinary projects, educational visits, etc.)

- develop educational material and instructional media,

- manage the weekly timetable according to the learners' needs,

- determine the local relationships of the school with other partners, and engage in cooperation with them.

In other words, SCSs adopt a mixed cooperative model of curriculum development and school reform. The pedagogy of multiliteracies shaped the general principles based on which each school and each educator would develop their own curriculum and define their own innovative practices. In this way, the importance of educators is recognised, since they play a key role in reshaping the curriculum and producing educational discourse in a cooperative framework (Kirk \& MacDonald 2001: 566).

\subsection{Research Data: Presentation and Analysis}

\subsubsection{The educators' attitude towards developing the curriculum at school level}

The unfamiliar process of curriculum development by educators created conflicting feelings. Some (12: 28,5\%) even stated that their initial reaction was ambivalent: feeling stress and embarrassment on the one hand, and satisfaction and anticipation on the other hand Initially, they were rather positive towards the process, with more answers that reveal acceptance of this practice (satisfaction: 18: $42 \%$, anticipation: 16: 38\%) than answers betraying reluctance (stress: 13: $31 \%$, embarrassment: $12: 28,5 \%$, bewilderment: $4: 9,5 \%$, fear: $2: 4,8 \%$ ). When asked to justify their positive attitude, educators focus on the 'feeling of freedom', the 'possibility for self-motivation', and the 'action without commitment', stating that such a curriculum development practice presents a challenge that 'motivates' them, allowing them to act in a 'exploratory' way, to relate the educational process with a specific situation and be 'creative'.

Educators who were initially reluctant attribute their stress and embarrassment not to the process itself, which they consider difficult and stressful because it is unfamiliar, but to the content, the material they have to find, the thematic units they have to create. It would seem that the educational system is too focused on subject matters to allow educators to overcome dominant beliefs on the role of content in the educational process (Kelly 2004: 97). Later on however, after having worked on curriculum development, the educators' orientation is considerably differentiated. Only few (8: 19\%) claim to have taken into account the syllabus 'that they had to cover'. It seems that their involvement in the process leads them towards other parameters that relate to the teaching act itself and emerge as more important.

The change in the educators' attitude is also demonstrated by the fact that they attribute less importance to organising the process based on pre-existing data (objectives they had predetermined 27: 64,2\%, existing Guidelines 23: 54,7\%), 
compared to data that emerged during the process, such as the climate that gradually developed in the school (29: $69 \%$ ) and, more importantly, the specific learners themselves (38: 90,5\%). For educators, assuming the responsibility for developing the curriculum opens a research perspective, which allows them to escape from the normative linear model and move on to an epistemology of practice, focusing on the parameters that influence it.

This is supported by the fact that curriculum development relied on a different basis. Although the initial approach of $3 / 4$ of educators is based on relevant literature, demonstrating their adherence to the notion that theory guides practice (Grundy 1987), during curriculum development educators focus on the particular circumstances of the school, as they perceive them. Moreover, most educators found that managing to develop a curriculum that meets the needs and interests of learners was the most interesting part of the process. As two educators characteristically state in their answers:

The most interesting part of curriculum development was:

'Matching the learners' needs and potential to the teaching objectives'

'Researching material that would interest the learners, so they wouldn't be afraid of new knowledge, nor consider it inaccessible and foreign'

In such a framework of autonomous action, the educators profess to be quite satisfied from the research practice in which they engaged through curriculum development. In their own words, this practice 'motivates' them, and 'renews [them], as they [...] do not stagnate repeating a specific syllabus', and attributes them 'an important responsible role in the educational process'. And they can feel the results, though not the measurable results of educational behaviourist models that are controlled through written exams; rather, the results emerge gradually through collective educational action and autonomous educational course, revealing the 'change of perspective in most learners, their positive response to experiential learning and self-esteem development', as an educator stated.

As the role of educators was upgraded and curriculum development gained a research perspective, another differentiation emerged. The vast majority of educators (39/42: 92,85\%) felt it was necessary to evaluate the specific curriculum. Curriculum evaluation emerged as an internal need, as the process evolved. For this reason, alternative forms of evaluation were utilised (Chatzigeorgiou 1998: 257), including open discussions with learners, evaluation sheets or questionnaires, systematic observation, keeping a journal, and maintaining an educator evaluation folder. Educators state they utilised these methods because they realised that 'the interaction between the people who participate in the process and the meanings they exchange form the main parameters for the evaluation of the process' (Smith 1998 in Chatzigeorgiou 1998: 257). That is, the evaluation was qualitative and functioned in a formative way, influencing the process and its alternative forms.

\subsubsection{Differentiated attitudes towards the educational process}

In this constantly changing framework, educators seem to perceive the educational act itself in a different way. It is no longer a linear process, achieved by implementing specific steps. Nothing is predetermined. Almost all educators attribute the constant need for review to three main parameters: a) the learners' needs, knowledge gaps and interests, b) the learners' learning pace, and c) current events, which would determine the subjects. The process had a new meaning for educators; it 'went someplace', as an educator stated. It gained value, not as a means to achieve other ends, but as a process of reflective research that reveals both the valuable aspects of the educational act and its problems, deficiencies and inconsistencies, which invite new research.

Learners emerge as protagonists in the process, either directly, as 'the learners themselves co-shaped the process with their suggestions', or indirectly, since for most educators, learners constituted the main parameter of curriculum development. Curriculum content was initially based on research on the learners' world of interests, to create thematic units, that is Freire's generative themes (Grolios 2004: 199), on which the process would be based. In their answers, most educators referred to their quest for subjects that would interest the learners. One educator states: 'The hardest part was finding interesting subjects on the one hand and then working on them in a way that would help them eliminate their stereotypical perceptions on the other hand'.

An important shift is apparent. According to the traditional modernist view, the learners' interests, even in the rare cases when they were acknowledged, were marginalised in the framework of explicit hierarchy and power distribution imposed by the educational structure (Brooker \& Macdonald 1999: 84), or were sacrificed for the sake of valid knowledge and skills, deemed necessary by scientific tradition and university administration or by the functional needs of society and the economy. However, in this case we can see that the curriculum is based on the classroom's culture, knowledge and social practices, validating the experiences brought to school by the learners (Aronowitz \& Giroux 1993: 151). No sooner do educators assume the responsibility for curriculum development, 
that they start focusing on the process, acting in a way that allows the learners' voice to be heard and even to constitute a main parameter of curriculum development.

Learners were not true participants in curriculum development, which remained the exclusive responsibility of educators. However, their indirect participation opened a new perspective for them. As educators gave learners the right to express their views, they had the opportunity to reflect on the process, to evaluate what and how they had learned (Boomer et al. 1992: 184). When learners were called to state their views, these had to be taken into account. So, indirectly, learners participated in decision-making.

This orientation had another equally important consequence. Having the responsibility for curriculum development and focusing on the learners' needs, potential, learning pace and interests, most educators realised that they had to recontextualise knowledge so as to make it more understandable to all and link it to everyday life, which they found to be the hardest part of the process. As if educators, most of which were quite experienced, were realising for the first time that the student population is heterogeneous. As if they understood for the first time the importance of utilising differentiated pedagogy (Sfiroera 2004). No sooner had educators stopped focusing on results and realised the value of the process itself that they started to understand that class homogeneity is a construct made by the designers of identical curricula for all learners of a country (Koutselini 2004: 124).

Most educators dealt with learner heterogeneity as a problem, which for some was hard to solve ('I thought it was impossible to meet the needs of all learners'), as they focused mainly on the learners' weaknesses; for others, it was a challenge ('I was concerned by learner heterogeneity, but I thought that managing it was a challenge and an opportunity for experimentation'), attributing the problem not to the learners but to the educators themselves, who had to develop the curriculum (Hart 1992: 138). For most educators, heterogeneity acted as a source of feedback, leading them to a process of constant evaluation in class, which allowed them to modify both the content and the learning processes.

Their autonomy and the culture of cooperation that gradually evolved led educators to another innovative intervention. They came to adopt, as they state, the view on the holistic approach to knowledge, which was latent in the Guidelines, accepting that a contemporary curriculum cannot be divided into subject matters according to how dominant groups divide sciences in the university (Goodson 1988: 177). They moved on to organise interdisciplinary projects, often stating that this was the most interesting part of the process, as they 'helped learners link knowledge to life and their everyday reality', 'making learners literate, as they understood an aspect of reality in a multifaceted way'.

\subsubsection{The role of collective action}

The whole process was influenced by the fact that the educators of each school formed a group that worked collectively to a certain extent, while each educator was a member of a wide network of educators working for the same purpose. As seen above, educators cooperated in the context of interdisciplinary projects and co-teaching sessions, while at the same time they had regular pedagogical meetings to discuss common problems, solutions they had been designing or implementing, and their results. Moreover, in the training seminars, educators cooperated with educators from other SCSs in groups that corresponded to each literacy, under the coordination of a thematic officer. The process was organised in a way that helped them act collectively, a fact that seems to have functioned positively.

A statistically important number of educators $(69 \%)$ declares that the gradually evolving climate of research and cooperation was an important parameter of curriculum development. Many sought support by colleagues in the same (17: $40,47 \%$ ) or other schools (10: $23,8 \%$ ). Some even state that they modified the curriculum in the context of cooperation with their colleagues, viewing this cooperation as particularly beneficial and supportive in their efforts. As an educator states: 'I had to adjust the curriculum to the learners' developing needs and the needs that emerged from the interaction with other classes'. 'I would modify my plans, as we provided each other with feedback and ideas' adds another educator.

In a relevant question (In your school, your colleagues developed their own curriculum, individually or in cooperation. Did this fact help you in the process?), most educators answered positively. $78 \%$ of educators state that curriculum development by all colleagues in the school provided each educator with support. According to the educators, their meeting points in this common parallel action were: their common concern about whether they would make it, the common objective of helping learners, and the joy they experienced from cooperating and learning from each other. Since all the school's educators participated in this parallel action, it allowed them to gain a 'multifaceted approach', providing them with 'ideas and stimuli', keeping them 'alert' and 'nurturing a creative climate'. Most importantly, it led them to common action, not only in terms of co-teaching sessions and 
interdisciplinary projects, but also in collective curriculum development.

The following excerpts from the educators' answers are indicative of their cooperative orientation and the resulting perspective of improvement:

'Curriculum design is not so different from one subject matter to the next, so the concerns and problems are the same. By discussing with others, you can feel that you are not alone'.

'We all tried to share this experience and our concerns, which was something new and very interesting. It often resulted in cooperation, making the curriculum more broad and flexible'.

'So, there is a multifaceted approach that benefits students and provides educators with a wide field of cooperation both in and out of the classroom. It offers a different perspective'.

As educators developed cooperation which arose naturally, they learned in the specific school context, and even from each other, in a constant process of individual and collective search. This brought changes on both how each perceived the process and the school's culture (Fullan 2005: 210). As they gradually enhanced the terms of their cooperation, set common objectives for the learning of all learners, activated various resources, exchanged ideas and joined in common searches, the school was gradually turned into a professional community of learning (Dufour 2004, Newmann et al. 2000 cited in Fullan 2005: 210).

Nevertheless, a number of educators $(8 / 42,19 \%)$ did not find this collective search supportive in their efforts. They attribute their negative or neutral attitude towards the collective-cooperative climate to the difference between subject matters, which does not allow for common speculation ('The content and needs of the subject matters are different, and the way of organising the teaching process is personal') and to their inability to cooperate. These, fortunately few, educators still nurture strong beliefs on the isolation of subject matters and knowledge sectors and the individual nature of their profession. Operating within the 'culture of positivism', these educators believe that school knowledge is an external body of information, which is produced independently from human beings (Giroux 1981: 52). They confirm the view that institutionalising knowledge through sciences and corresponding subject matters limits the potential of both educators and learners for independent action and restricts their opportunities to create links and associations that give meaning to the educational process (MacDonald 2003: 144).

\subsubsection{Meaning attributed to the curriculum}

\subsubsection{In the classroom microlevel}

Educators who have participated in developing curriculum in their school attribute a completely different meaning to the curriculum. 40 out of 42 educators state this explicitly. For most, when they worked in conventional education and were given a curriculum in form of a package, a product to be consumed, they viewed the curriculum as a commitment and a limitation. In their own words, the curriculum was 'strictly bound', 'couldn't adapt to the needs of educators or learners', meant to 'operate focused on quantity instead of quality', for an education that 'lacked imagination, that was suspicious, outdated, focused on results', which 'stops educators from developing a relationship with their students' and doesn't allow them to 'develop a more personal relationship with knowledge and the joy of knowledge'. The curriculum was a homogeneous product, focused on the syllabus, which should be transmitted without modifications in schools with different student populations and particular characteristics. It was limiting, bounding and actually inefficient for educators who did not follow the dominant 'norm' and the ways of mastering knowledge that are imposed and legalised by it.

From the beginning of their career, most educators (70\%) perceived it as an intrusive and leading text, which they consulted in the beginning of the school year (42,5\%), when they were first appointed as educators (38\%) or when a new, always top down, curriculum was composed $(35,7 \%)$. For few educators $(28,5 \%)$ the curriculum was a stimulus for speculation, consulted after attending a seminar.

An important consequence of viewing the curriculum as a product is the division between theory and practice or the hierarchical domination of theory, which guides, confirms and validates practice (Grundy 1987: 65). Most participant educators consider curricula developed by experts/scientists to be 'far away from classroom reality', 'distanced from education', expressing the belief that academic theory, developed in universities and research centres, cannot be utilised to enhance the educational act.

However, the educators' experience from participating in curriculum development in their school changes their attitude completely, and the curriculum assumes different meaning. Educators focus on its dynamics ('a dynamic tool in our hands', 'it cannot be standardised and static'), its ability to (re)adjust itself to the learners' needs and interests ('it is constantly adapted to the dynamics of the classroom or group of learners', 'I now manage it more easily and 
knowledgeably to aptly modify it according to the learners' needs'), and its research potential ('the processes it recommends are never fixed and should be constantly investigated', 'I view it differently, as part of a search for knowledge', 'I am constantly challenging it, so it is a motivation for improvement'). Few educators now identify the curriculum with commitment and limitation $(16,7 \%)$, which relate to external factors and are no longer considered important by educators.

In contrast, through their involvement educators realise the importance of the framework of the educational act in shaping the process. The validity of educational theory is not controlled by external agents, but judged in the school context (Keiny 1993: 67), where theory can be neither fixed and objective nor a specific norm accessible only by studying the literature. Yet participant educators do not attempt to describe a practical theory emerging from researching practice, what Elliott called 'practical wisdom' (Elliott 1993). They refer to educational practice as the basis of the educational process, perhaps promoting an overly practical view of education.

Several educators state that such a non static and fixed curriculum calls for research and change, requiring 'reflection' and a 'critical attitude'. Only reflective educators can comprehend the framework in which they are to intervene, utilising their practical knowledge to attempt to create a learning environment that is meaningful for their learners (Grundy 1987: 67). For this reason, some participating educators view it as 'a difficult task', which at the same time is experienced as 'creative and efficient for learners'. The number of educators who consider the curriculum as a stimulus for reflection has almost doubled after their SCS experience, rising from 12 to 21 out of a total of 42 .

\subsubsection{In the sociocultural context macrolevel}

As can be seen in their answers, participant educators do not directly relate the curriculum with the school's social and cultural context, nor do they perceive it as the result of political and ideological choices. They only relate it to a broad cultural framework when they criticise the dominant curriculum development practice in the context of educational policy in conventional education. They criticise the fact that curricula are 'written to meet European goals' or 'depending on market conditions', by experts who are 'unfairly chosen not on the basis of their scientific skills but due to their political party allegiance'. However, their alternative practice is not based on an explicit ideological choice, nor does it result from reflection that exceeds the limits of the school institution. Few educators $(16,7 \%)$ viewed the curriculum as a political - ideological text when they here first appointed, and the percentage hasn't risen since.

Even when educators refer to specific learners and their particularities, they mostly focus on their learning pace, neglecting to address their social or cultural origin. Although educators often refer to the learners' life experiences, on which curriculum development is based, it remains unclear to which extent these experiences form the basis for speculation and critical elaboration, whether educators critically approach and investigate how learners perceive and interpret their experiences, in the context of empowering learners and nurturing their critical awareness (Aronowitz \& Giroux 1993: 151).

Absorbed in the change of orientation of the educational process, educators feel satisfied with innovations that address what and how, rather than express why. Many educators declare their desire to modify thematic units according to the learners' interests, so as to improve the process. The educational act concerns the limited boundaries of the school, as if it took place in a politically neutral educational framework. This view is typical of traditional curriculum development (Pinar et al. 1996: 313), and fails to address the educators' choices as political, as the product of a historically, culturally and socially structured hierarchy.

Educators view their autonomy as a liberating situation. Since the linear development of the educational process is no longer forced on them, they are allowed to make conscious choices. However, this does not engender speculation on the broad cultural context influencing their choices, and the dominant discourses that are latent both in their choices and in the learners' expectations. They are not concerned with how they could de-naturalise these discourses, though this could form the basis for a political emancipatory perspective (McLaren 1991: 248).

\section{Conclusions}

The development of the curriculum by educators has given a different perspective to the educational process, which seems, according to their statements, to be the result of their conscious choices and draw on the real needs of the classroom, as they evolve in the context of an active and dynamic process. The educators of the sample seemed able to realise the benefits of their liberation from a predefined imposed model, and overcame the epistemology of explaining and controlling, moving on to the epistemology of practice, replacing manipulation with judgement (Stenhouse 1975). This practice has permanently changed their attitude towards the curriculum, as can be seen in the 
following statement:

'I have not returned to conventional schools. After my experience in SCS, it would be too hard to deal with conventional school curriculum. I would languish'

The research showed that this bottom up development of curriculum and educational change was able to function as the school was turned into a research laboratory, not only for learners but also for educators. By exchanging thoughts and ideas, by engaging in cooperation and sometimes in collective action, by gradually liberating themselves from the insecurity of criticism, by maintaining open channels of communication, the educators were able to function as a professional community of learning. And it seemed that such a community offers educators significant support.

However, this innovative practice was also developed due to another element, as seen in relevant literature (Katsarou \& Tsafos 2008). A broad framework supported it, in the context of overall SCS enhancement. The scientific committee, responsible for implementing the European programme, supported the process of this investigative innovative practice, attributing a cooperative form to curriculum development (Fullan 1994): The curriculum was designed based on the Teaching Guidelines, which provided a broad and open framework that was tried out in practice and then reshaped based on feedback and evaluation. The reshaping process was based both on the qualitative evaluation of the process by all participants and on discussions during pedagogical meetings in each school and educational meetings with all schools, which formed a network in this sense.

The educators of the sample seem to realise the value of this cooperative practice of curriculum development, mainly on school level. Few refer to the broader educational framework and the networking of schools and educators. They are bound by the limits of the school and everyday educational practice, which they do not approach in the context of broader speculating on education and reflecting on their own professional identity as a product of ideological choices. This is why they fail to recognise the political nature of the educational act (Grolios et al 2003: xxxi). In this way, they view curriculum development in a limited and instrumental way, as a step in enhancing the curriculum to meet local needs.

This was an important step, perhaps the first step in the course towards autonomy, achieved through conscious choices. This step opened up new perspectives for educators, it did not simply help them criticise the existing situation, as a participating educator explicitly states:

'The study of the curriculum, of the relationship of students and educators with time, real needs and their interests is one of the most fundamental issues in an educational reform. And one of the most neglected. Greek schools lack freedom, research and pleasure'

Nor did it simply allow them to act as researchers aiming to enhance the educational process. It actually supported and reinforced them in their emerging aim to envision an expanded alternative practice, as explicitly put by a participating educator in the following excerpt:

'The curriculum in secondary education should have been jointly created by innovative processes and an expanded institutional framework, as has been the case of the European pilot programme on SCSs for the past ten years' (Educator of Kallithea SCS)

\section{References}

Androussou, A. (Ed.). (2007). Keys and master keys. Athens: Ministry of Education, University of Athens. [Text in Greek]

Apple, M. (1988). Social crisis and curriculum accords. Educational Theory, 38(2), $191-201$. http://dx.doi.org/10.1111/j.1741-5446.1988.00191.x

Aronowitz, S., \& Giroux, H. (1993). Postmodern Education. Minneapolis: University of Minnesota Press.

Autio, T. (2003). Postmodern Paradoxes in Finland: The Confinements of Rationality in Curriculum Studies. In W. Pinar, (Ed.), International Handbook of Curriculum Research (pp. 301-328). Mahwah, New Jersey, London: Lawrence Erlbaum Associates Publishers.

Boomer, G., Lester, N., Onore, C., \& Cook, J. (Eds.). (1992). Negotiating the curriculum: educating for the 21st century. London: The Falmer Press.

Brooker, R., \& Macdonald, D. (1999). Did we hear you?: issues of student voice in a curriculum innovation. Journal of Curriculum Studies, 31(1), 83-97. http://dx.doi.org/10.1080/002202799183313 
Chatzigeorgiou, G. (1998). Knowing the curriculum. General and specific issues on the curriculum and teaching. Athens: Atrapos. [Text in Greek]

Doll, W.E. (1993). A Post-modern Perspective on Curriculum. New York: Teachers College Press.

Dufour, R. (2004). What is a "professional learning community"? Educational Leadership, 61(8), 6-11.

Elliott, J., (Ed.). (1993). Reconstructing teacher education: Teacher development. London: The Falmer Press.

Flouris, G. (1995). Curricula for a new era in education. Athens: Grigoris. [Text in Greek]

Freire, P. (1972). Pedagogy of the Oppressed. Harmondsworth: Penguin.

Fullan, M. (1994). Coordinating bottom-up and top-down strategies for education reform. In R. Elmore \& S. Fuhrman (Eds.), The governance of curriculum (pp. 186-202). Alexandria, VA: Association for Supervision and Curriculum Development.

Fullan, M. (2005). Professional Learning Communities. Writ large. In R. Dufour, R. Eaker, R. Dufour (Eds), On Common Ground (pp. 209-223). Bloomington, Indiana: National Education Service.

Giroux, H. (1981). Ideology, Culture and the Process of Schooling. Barcombe: Falmer Press.

Goodson, I. F. (1988). The Making of Curriculum: Collected Essays. London: Falmer.

Grolios, G. (2005). Paulo Freire and the Curriculum. Thessaloniki: Vanias. [text in Greek]

Grolios, G., (2004). Elements of Paulo Freire's contribution in curriculum design. In G. Bagakis (Ed.), The educator and the curriculum (pp. 198-204). Athens, Metaihmio. [text in Greek]

Grolios, G., Karantaidou, R., Korobokis, D., Kotinis, Ch., \& Liambas, T. (2003). Literacy and awareness: a pedagogical approach based on Paulo Freire's theory. Athens: Metaihmio. [text in Greek]

Grundy, S. (1987). Curriculum : Product or Praxis? London - New York \& Philadelphia: The Falmer Press.

Hargreaves, A. (1994). Changing Teachers, changing times: teachers work and culture in a postmodern age. London: Cassell.

Hargreaves, A. (2000). Professionalism and professional learning. Teachers and Teaching, Theory and Practice, 6(2), 151-182. http://dx.doi.org/10.1080/713698714

Hart, T. S. (1992). Differentiation. Part of the problem or part of the solution? Curriculum Journal, 3(2), 131-142. http://dx.doi.org/10.1080/0958517920030203

Ioannidou-Koutselini, M. (2001). Curriculum development: theory-research-practice. Nicosia: Pedagogical Institute. [text in Greek]

Katsarou, E., \& Tsafos, V. (2008). Collaborative school innovation project as a pivot for teachers' professional development: the case of Acharnes' Second Chance School in Greece. Teacher Development, 12(2), 125-138. http://dx.doi.org/10.1080/13664530802038139

Keiny, S. (1993). School Based Curriculum Development. Educational Action Research, 1(1), 65-93. http://dx.doi.org/10.1080/0965079930010105

Kelly, A.V. (2004). The Curriculum. Theory and Practice ( $5^{\text {th }}$ ed.). London: Paul Chapman.

Kirk, D., \& Macdonald, D. (2001). Teacher Voice and ownership of curriculum change. Journal of Curriculum Studies, 33(5), 551-567. http://dx.doi.org/10.1080/00220270010016874

Lawton, D. (1980). The Politics of the School Curriculum. London: Routledge and Kegan Paul.

Macdonald, D. (2003). Curriculum change and the post-modern world: is the school curriculum-reform movement an anachronism? Journal of Curriculum Studies, 35(2), 139-149. http://dx.doi.org/10.1080/00220270210157605

McLaren, P. (1989). Life in Schools. An introduction to critical pedagogy in the foundations of education. New York: Longman.

McLaren, P. (1991). Decentering culture: postmodernism, resistance and critical pedagogy. In N. Wyner (Ed.), Current perspectives of the culture of schools (pp. 231-257). Boston, MA: Brookline Books.

Munby, H., \& Russell, T. (1989). Educating the reflective teacher: An essay review of two books by Donald Schön. Journal of Curriculum Studies, 21(1), 71-80. http://dx.doi.org/10.1080/0022027890210106

Norris, N. (Ed.). (2008). Curriculum and the Teacher: 35 years of the Cambridge Journal of Education. Oxon: 
Routledge.

Papastephanou, M., \& Koutselini, M. (2006). Reason, language and education: philosophical assumptions for new curricular orientations. Pedagogy, Culture \& Society, $\quad 14(2), \quad$ 149-169. http://dx.doi.org/10.1080/14681360600738319

Pinar, W.E. (2004). What is Curriculum Theory. Mahwah, New Jersey: Lawrence Erlbaum Associates.

Pinar, W.F., Reynolds, W.M., Slattery, P., \& Taubman, P.M. (1995). Understanding curriculum: an introduction to the study of historical and contemporary curriculum discourses. New York: Peter Lang.

Ruddock, J., \& Hopkins, D. (1985). Research as a basis for teaching: Readings from the work of Lawrence Stenhouse. Oxford: Heinemann.

Schön, D. (1983). The Reflective Practitioner. New York: Basic Books.

Sfyroera, M. (2007). Differentiated pedagogy. In A. Androussou (Ed.), Keys and master keys. Athens: Ministry of Education, University of Athens. [Text in Greek]

Stenhouse, L. (1975). An Introduction to Curriculum Research and Development. London: Heinemann.

Tsafos, V. (2008). Implementing an innovative programme: The ambiguity between the teachers' emancipatory professional development and the bureaucratic administrative control. The case study of the Second Chance School (SCS) in Attica's Acharnes. Scientific Review of Lifelong Learning, 1(1), 12-32.

Westbury, I. D. (1998). Didaktik and curriculum studies. In B. B. Gundem \& S. Hopmann (Eds.), Didaktik and/or curriculum: An International dialogue (pp. 47-78). New York: Peter Lang. 